\title{
The frequency and consequences of head injury in epileptic seizures
}

\author{
D L RUSSELL-JONES, S D SHORVON \\ From the Institute of Neurology, National Hospital for Nervous Diseases and the National Society for Epilepsy \\ Research Group
}

SUMMARY The frequency and sequelae of head injury in epileptic seizures were assessed. Two hundred and fifty five resident patients with chronic long term epilepsy (165M,90F) of average age 54 years were studied for a year and 43 patients in a short term assessment unit $(22 \mathrm{M}, 21 \mathrm{~F})$ of average age 26 years were studied for a month. A total of 27934 seizures were recorded, of which $12626(45 \cdot 2 \%)$ were associated with falls. There were 766 significant head injuries. Four hundred and twenty two required simple dressing and observation, and 341 required sutures (average number of sutures $4 \cdot 5$ ). There was one confirmed skull fracture, one confirmed extradural haemorrhage and one confirmed subdural haemorrhage. Thus $2.7 \%$ of all seizures resulted in a head injury $(6 \cdot 1 \%$ of seizures associated with falling). Simple dressing was required in $1.5 \% ; 1.2 \%$ required sutures. Only one in every 9311 seizures (one in every 4208 seizures associated with falls) resulted in skull fracture, extradural or subdural haemorrhage. Minor seizure related head injury is therefore relatively common, while severe head injury is rare.

As many epileptic seizures result in falls, it is clear that epileptics might have a higher incidence of head injury. The clinical consequences may range from trivial injury to skull fractures, contusion or cerebral haemorrhage. It has also been suggested that repeated head injury may result in intellectual decline. ${ }^{1}$ How prevalent or significant is head injury in a population of epileptic patients is not known. Little research has been carried out to study the extent of this problem, and differing conclusions have been reached. ${ }^{2}$ Annegers $^{3}$ found on review of patients admitted with head injury that the number of epileptics was not increased above that expected but Hauser ${ }^{4}$ found three times the expected number (however the prevalence of epilepsy in this study population was subsequently shown to be higher than originally estimated ${ }^{2}$ ).

Because of the obvious problems in performing such epidemiological studies in a general population we decided to study a population of subjects with epilepsy resident at the Chalfont Centre for Epilepsy, consisting of a heterogeneous group of both long stay and short term assessment patients. The Chalfont Centre is an ideal environment to undertake such studies as (1)

Address for reprint requests: Dr S Shorvon, Institute of Neurology, National Hospital for Nervous Diseases, Queen Square, London WCIN 3BG, UK.

Received 30 September 1988 and in revised form 9 January 1989. Accepted 16 January 1989 there are large numbers of patients, who live with medical attendants and helpers (we studied 298 patients), (2) there are large numbers of seizures, (3) all injuries, however trivial, are seen in a central casualty where an assessment is made, and (4) all patients have up-to-date seizure charts and seizure descriptions, completed by medical attendants, helpers, patients and fellow patients.

The aim of this study was to assess the frequency and characteristics of seizure-related head injury in patients with epilepsy.

\section{Methods}

Both chronic long term and short term assessment unit patients were studied. The chronic long term patients were studied for one year (1 March 1987 to 1 March 1988), the short term assessment unit patients were studied for one month (1 February 1988 to 1 March 1988) because of their shorter duration of admission (and results extrapolated to annual estimates). Two hundred and fifty five chronic long term patients and 43 short term assessment unit patients were studied. The total number and type of seizures in the study period were recorded in all patients and the number of seizures resulting in falls in a random sample of the chronic long term patient population (total $81,44 \mathrm{M}, 37 \mathrm{~F}$ ) and all the short term assessment unit patients. The percentage of seizures resulting in falls was recorded. This took account of witnessed or self reported falls associated with seizures. Patients with pseudoseizures were excluded. 
Table 1 The patient population and total numbers of seizures per group

\begin{tabular}{|c|c|c|c|c|c|c|}
\hline & $\begin{array}{l}\text { Number of } \\
\text { patients }\end{array}$ & Sex & $\begin{array}{l}\text { Mean age } \\
\text { (years) }\end{array}$ & $\begin{array}{l}\text { Total number } \\
\text { seizures/year }\end{array}$ & $\begin{array}{l}\text { Mean number } \\
\text { seizures/year }\end{array}$ & $\begin{array}{l}\text { Range } \\
\text { per year }\end{array}$ \\
\hline $\begin{array}{l}\text { Chronic long term patients } \\
\text { Assessment unit patients } \\
\text { Total }\end{array}$ & $\begin{array}{r}165 \\
90 \\
22 \\
21 \\
298\end{array}$ & $\begin{array}{l}\mathbf{M} \\
\mathbf{F} \\
\mathbf{M} \\
\mathbf{F}\end{array}$ & $\begin{array}{l}53 \cdot 4 \\
56 \cdot 3 \\
27 \cdot 7 \\
24 \cdot 5\end{array}$ & $\begin{array}{r}8540 \\
5882 \\
8544 \\
4968 \\
27934\end{array}$ & $\begin{array}{r}52 \\
66 \\
388 \\
236\end{array}$ & $\begin{array}{l}0-702 \\
0-337 \\
0-1500 \\
0-600\end{array}$ \\
\hline
\end{tabular}

All patients at the Chalfont Centre who fall and sustain a significant head injury are referred to the casualty department and to assess the number of significant head injuries we used the centre's casualty register. A significant head injury is defined as an injury with obvious head trauma and/or one in which the experienced attendants at the centre request casualty referral. The number of patients requiring simple dressing (a "minor" head injury), suturing, the numbers showing fractures on skull radiographs and the numbers referred for neurosurgical or orthopaedic advice are recorded.

A total of 13 patients were excluded, three because their seizure charts were missing, and 10 because they died of nonhead injury related illnesses (nine out of 10 had post mortem examinations).

\section{Results}

The results are shown in tables 1-3. The chronic long term patients are older and have less frequent fits than the short term assessment unit patients (table 1). The range in total seizures per year between each individual patient is shown in table 1 , and the subpopulation of chronic long term patients that was studied for seizure related falls was not significantly different from the chronic long term population as a whole.

Of the total seizures in the male and female chronic long term patients $47 \%$ and $55 \%$ respectively ended in falls. This compares with $40 \%$ and $48 \%$ respectively in the male and female short term assessment unit patients. Thus, an average of $45 \cdot 2 \%$ of all seizures end in falls (see table 2).

The assessment of the number of seizures ending in falls is considered accurate. It is quite possible, however, that other seizure types such as absence attacks or partial seizures which do not result in falls, or nocturnal attacks, may pass unnoticed by patient and staff and are therefore under-reported. The extent of this under-reporting is uncertain, but may be in the region of $5-20 \%$. With this proviso, we calculate that, over the twelve month period at the centre, there were 27934 fits and 12626 fits associated with falls which produced a total of 766 head injuries (422 minor, 341 requiring sutures, one clinical skull fracture, one clinically apparent subdural haemorrage confirmed by

Table 2 The proportion of seizures resulting in falls

\begin{tabular}{|c|c|c|c|c|c|c|}
\hline & $\begin{array}{l}\text { Number of } \\
\text { patients }\end{array}$ & Sex & $\begin{array}{l}\text { Mean age } \\
\text { (years) }\end{array}$ & $\begin{array}{l}\text { Total number } \\
\text { seizures/year }\end{array}$ & $\begin{array}{l}\text { Mean number } \\
\text { seizures/year }\end{array}$ & $\begin{array}{l}\% \text { Seizures } \\
\text { producing falls }\end{array}$ \\
\hline $\begin{array}{l}\text { Chronic long term patients } \\
\text { Assessment unit patients }\end{array}$ & $\begin{array}{l}44 \\
37 \\
22 \\
21\end{array}$ & $\begin{array}{l}\mathbf{M} \\
\mathbf{F} \\
\mathbf{F}\end{array}$ & $\begin{array}{l}55 \cdot 6 \\
59 \cdot 0 \\
27 \cdot 7 \\
24 \cdot 5\end{array}$ & $\begin{array}{l}1972 \\
2679 \\
8544 \\
4968\end{array}$ & $\begin{array}{r}45 \\
72 \\
388 \\
236\end{array}$ & $\begin{array}{l}47 \% \\
55 \% \\
40 \% \\
48 \%\end{array}$ \\
\hline
\end{tabular}

(The proportion of seizures resulting in falls was assessed in a subgroup of 81 chronic long term patients, and all patients in the short term assessment unit.)

Table 3 Consequences of head injury due to seizures

\begin{tabular}{|c|c|c|c|c|c|}
\hline Title & $\begin{array}{l}\text { Total number } \\
\text { of seizures } \\
\text { per year } \\
(n=27934)\end{array}$ & $\begin{array}{l}\text { Total number } \\
\text { of seizure/ } \\
\text { injury }\end{array}$ & $\begin{array}{l}\% \text { Total } \\
\text { seizures resulting } \\
\text { in injury }\end{array}$ & $\begin{array}{l}\text { Total number } \\
\text { seizures which } \\
\text { produce falls } \\
\text { per injury } \\
(n=I 2626)\end{array}$ & $\begin{array}{l}\text { \% Seizures } \\
\text { which produce } \\
\text { falls per } \\
\text { injury }\end{array}$ \\
\hline $\begin{array}{l}\text { Head injury (simple dressing) } \\
\text { Head injury (sutures)* } \\
\text { Confirmed fracture } \\
\text { Confirmed subdural haemorrhage } \\
\text { Confirmed extradural haemorrhage } \\
\text { Total number head injuries }\end{array}$ & $\begin{array}{r}422 \\
341 \\
1 \\
1 \\
1 \\
766\end{array}$ & $\begin{array}{c}66 \cdot 2 \\
81 \cdot 9 \\
27934 \\
27934 \\
27934 \\
36 \cdot 5\end{array}$ & $\begin{array}{l}1 \cdot 5 \\
1 \cdot 2 \\
0 \cdot 0035 \\
0 \cdot 0035 \\
0.0035 \\
2 \cdot 7\end{array}$ & $\begin{array}{r}29 \cdot 9 \\
37 \cdot 0 \\
12626 \\
12626 \\
12626 \\
16 \cdot 5\end{array}$ & $\begin{array}{l}3 \cdot 3 \\
2 \cdot 7 \\
0 \cdot 0079 \\
0 \cdot 0079 \\
0 \cdot 0079 \\
6 \cdot 1\end{array}$ \\
\hline
\end{tabular}

*Average number of sutures $4 \cdot 5$ (range $1-17$ ). 
CT and one clinically apparent extradural haemorrhage confirmed by CT (table 3 )).

There is thus a head injury of sufficient severity to require medical attention once in every 36.5 seizures, and once in every 16.5 seizures resulting in a fall. There is one clinically apparent subdural or extradural haemorrhage requiring neurosurgical advice per 27934 total fits and per 12626 fits associated with falls.

\section{Discussion}

The patients resident at the Chalfont Centre are encouraged to lead as normal a life as possible, with normal domestic arrangements and daily activities. Thus, although our study is of an isolated community, it may be taken to be representative of chronic epileptics as a whole.

Head injury is perceived as a particular problem for patients who suffer with epilepsy yet there are few statistical studies and the extent or consequences of head injury are not clearly known.

There are a number of approaches to study the frequency of head injury in epileptic patients. ${ }^{2}$ Firstly it is possible to assess how many patients who present with a head injury have epilepsy. The studies of Anneger ${ }^{3}$ and Hauser ${ }^{4}$ are examples; their conclusions and results differ and are difficult to interpret.

The second approach is to assess the frequency of head injury within an epileptic population. BrochutGrollier ${ }^{5}$ performed a retrospective study looking at 4000 case notes of patients suffering with epilepsy and found the number of "accidents" to be low, but the study depends on the accuracy and interest of the doctor who kept the medical records and only severe injuries were documented. Sonnen et $\mathrm{al}^{2}$ studied 604 patients over a period of 3-7 months. Three hundred and seventy one were out-patients and 133 were inpatients. They looked at "accidents" and found there was one accident per 500 seizures. This low frequency is in contrast to our study However, "accidents" were not clearly defined, his study population was in part out-patient and there is no mention of Sonnen's methods in deriving this figure. Allen and Oxley ${ }^{6}$ have shown from a smaller study on the same population at the Chalfont Centre that fractures are more easily sustained during tonic seizures (those in which patients fall rigidly to the ground). Lidgren et al ${ }^{7}$ studied fractures in an epileptic population and it is interesting that they did not report any skull fractures.

In the 298 patients studied, 27934 seizures were recorded (12 626 with falls), and a head injury requiring casualty referral occurred once in every 36.5 $(2 \cdot 7 \%)$ seizures and once in every $16 \cdot 5(6 \cdot 1 \%)$ seizures resulting in a fall. Suturing was required for one in every 82 seizures, and one in every 37 seizures with a fall. Despite this, only one skull fracture and two cerebral haemorrhages were detected; an incidence of serious injury of $1 / 9311$ seizures or $1 / 4208$ seizures with falling. These results are subject to several sources of potential inaccuracy, but it seems likely that these introduce only a small error. The seizure charts, although kept meticulously up-to-date will have failed to record seizures which were unreported or unwitnessed, and this will apply to minor attacks, or some nocturnal attacks. Seizures resulting in falls would have been recorded in almost all cases. Thus, although the percentage of seizures resulting in falls $(45 \%)$ must be considered a high estimate (with perhaps a $5-20 \%$ error), the actual number of seizures resulting in falls (12 626) is reliable. If one assumed even a $20 \%$ underreporting of minor seizures, the proportion of seizures resulting in falls would still be of a similar order $(38 \%)$. Similarly, because of the centralised system of casualty referral, the number of head injuries is accurate. It is also highly unlikely that intracranial haemorrhage or fracture were not clinically detected, as almost all patients dying in the centre over the past 10 years have had post mortem examination, and unsuspected cerebral haemorrhage or skull fracture are rare. In the study period of 12 months only one extradural and one subdural haemorrhage occurred, but from a review of the records of previous years, it seems clear that subdural hamorrhage is a more common result of head injury in epilepsy than extradural haemorrhage.

An issue which the study did not address is that of the intellectual deterioration that may accompany head injury in epilepsy. A small proportion of patients with epilepsy do show progressive intellectual decline, which has been attributed to head injury by some authors.' We have, however, encountered patients without falls or head injury who have shown this phenomenon, and we consider the contribution of head injury to this process to be uncertain. Another interesting finding in patients with epilepsy, which may protect against the consequences of head injury, is thickening of the skull vault which is consistently seen on CT or skull radiology. This phenomenon has not been fully studied.

In this study, it surprised us to find that so few seizures result in severe head injury. Of the estimated 12626 falls, only one skull fracture was identified and only two clinically apparent cerebral haemorrhages. Whether this is due to the protective effect of thickening of the skull vaults is not known, and this would deserve further study. This is not to say that head injury in epilepsy is a minor problem, as the intellectual consequences of repeated head injury in epileptics is unknown. Intellectual deterioration in boxers, who have also sustained repeated head injuries, has been documented, and longitudinal studies of head injury in epilepsy are under way. Finally, it has been said that 
only patients who fall stiffly are at risk (such as patients with tonic or tonic clonic seizures), and not those who fall with atonia. We did not analyse our findings in regard to seizure type because we did not witness all the seizures ourselves. Nevertheless, our clinical experience and experience from this study suggests that this may be an important factor. In the Chalfont population, there is a higher proportion of tonic and atonic seizures than amongst the generality of epileptic patients, and the frequency of severe head injury may thus be higher in this group than in a less selected population; but this bias is likely to have a small statistical influence.

We thank the patients, nursing staff and helpers at the Chalfont Centre for their help in conducting the study and thank Dr J Oxley for his advice and support.

\section{References}

1 Thompson P, Sander J. Intellectual Deterioration in Severe Epilepsy. In: Wolf P, Dam M, Janz D, Dreifuss F, eds. Advances in Epileptology, Vol 16. New York: Raven Press, 1987.

2 Sonnen A, van Eil A, Erkens A, Larsen C, Belleman W. Is Epilepsy a dangerous condition? Monograph Dr Hans Berger. Breda, Holland, 1984.

3 Annegers J, Grabow J, Groover R, Laws E, Elveback L, Kurland L. Seizures after head trauma: a population study. Neurology 1980;30:683-9.

4 Hauser W, Tabaddor K, Factor P, Finer C. Seizures and head injury in an urban community. Neurology 1984;34:746-51.

5 Brochut-Grollier C. La Dangerosité de L'Epileptique. Thesis. Lille, 1983.

6 Allen J, Oxley J. Fractures in patients with epilepsy. In: Oxley J, ed. Antiepileptic Therapy: Chronic Toxicity of Antiepileptic Drugs. New York: Raven Press, 1983.

7 Lidgren L, Walloe A. Incidence of fractures in Epileptics. Acta Orthop Scand 1977;18:356-61. 